\title{
IPTEKS PERAN PENGAWASAN BPKP DALAM MENGAWAL DAN MENGOPTIMALKAN PENERIMAAN NEGARA
}

\author{
R. Haryo Wiratama Adi ${ }^{1}$, Inggriani Elim ${ }^{2}$ \\ ${ }^{1,2}$ Jurusan Akuntansi, Fakultas Ekonomi dan Bisnis, Universitas Sam Ratulangi, Kampus Unsrat, Sulawesi \\ Utara, 95115, Indonesia \\ E-mail : Haryowiratama2@gmail.com
}

\begin{abstract}
Non-tax state revenues are sources of Indonesian state revenues originating from levies paid by individuals or entities, where all proceeds of such revenues are managed by the government in which the proceeds from the direct or indirect benefits of services and utilization of resources and rights obtained from the state, based on taxation legislation. The purpose of this study is to ensure that government bureaucracy (governance) punishes achieving goals by implementing risk management and control. BPKP as an APIP that has authority based on the law and presidential regulation in the management of PNBP, must be proactive, initiative, anticipative to help formulate, plan, implement policies for monitoring PNBP management.
\end{abstract}

Keywords: government internal control apparatus, goverment, regulation in the managemeent of PNBP

\section{PENDAHULUAN}

Menurut Undang-Undang No. 17 tahun 2003 dijelaskan bahwa semua penerimaan bersumber dari penerimaan perpajakan, PNBP serta penerimaan hibah dalam dan luar negeri merupakan pendapatan Negara dari Kementrian Keuangan atas persetujuan presiden yang dibahas dengan DPR bahwa sumber pendapatan negara berasal dari 3 sektor : Pajak, Non Pajak, dan hibah. Semua pendapatan dan penerimaan pajak negara akan kembali ke masyarakat dalam bentuk program bantuan kesehatan, pendidikan, jaminan sosial dan infrakstruktur. Semua pendapatan negara yang dikelola dengan baik nantinya akan digunakan untuk membenahi dan meratakan ekonomi rakyat sebagai perwujudan sila 5 yaitu keadilan sosial bagi seluruh rakyat Indonesia. Pajak, non pajak, dan hibah dalam negeri maupun luar negeri merupakan sumber pendapatan negara.

Pajak di andalkan di setiap negara terutama negara berkembang karena menjadi sumber pendapatan utama. Saat ini jenis pajak yang di kelola oleh Direktorat Jendral Pajak Contohnya PPH,PPN, PPnBM, PBB, Pajak Ekspor, perdagangan internasional serta Bea Materai. Dalam proses pembangunan daerah membutuhkan adanya suatu sistem perencanaan pembangunan yang baik. Namun, keberhasilan prosesnya membutuhkan adanya fungsi pengawasan melalui sistem pengendalian intern yang andal agar agenda pembangunan yang tertuang dalam dokumen perencanaan dapat tercapai.

Melalui Peraturan Pemerintah (PP) No 60 Tahun 2008 tentang Sistem Pengendalian Intern Pemerintah (SPIP), Badan Pengawasan Keuangan dan Pembangunan (BPKP) melakukan pembinaan mengawasi intern atas menyelenggarakan Peran dan Fungsi lembaga pemerintah sesuai Akuntabilitas keuangan negara \& membina penyelenggaraan SPIP.berdasarkan Peraturan Presiden No 192 tahun 2014 dan Instruksi presiden no 9 tahun 2014.Badan Pengawasan Keuangan dan Pembangunan (BPKP) mempunyai Peran dalam melaksanakan usaha yang berkaitan dengan Pemerintah di bidang pengawasan Keuangan Daerah/Negara dan membangun Infrakstruktur Nasional.

Dalam melakukan tanggung jawab Badan Pengawasan Keuangan dan Pembangunan 
(BPKP) melakukan 2 pekerjaan utama tersebut yaitu Fungsi pengawasan intern \& Fungsi mengarahkan dan mengkoordinasikan pengawasan intern dan fungsinya. Fungsi ini meliputi fungsi Merumuskan kebijakan nasional untuk mengawasi sistem intern pada akuntabilitas keuangan Daerah/Negara serta membangun Infrakstruktur nasional, dan fungsi untuk pengkoordinasian dan sinergi dalam penyelenggaraan pengawasan intern bekerja sama dengan para aparat pengawasan intern pemerintah lainnya.

\section{TINJAUAN PUSTAKA}

Tugas Pokok dan Fungsi BPKP dalam Mengawasi \& Optimalisasi Penerimaan Negara bukan pajak Melalui Kepres No. 192 tahun 2014. Proses pelaksanaan pembangunan daerah membutuhkan adanya suatu sistem perencanaan pembangunan yang baik dan keberhasilannya membutuhkan adanya fungsi pengawasan melalui Sistem Pengendalian Intern (SPI) yang andal agar agenda pembangunan yang tertuang dalam dokumen perencanaan dapat tercapai. Melalui Peraturan Peraturan Pemerintah (PP) No 60 Tahun 2008 tentang SPIP, Badan Pengawasan Keuangan dan Pembangunan (BPKP) melakukan pembinaan intern atas menyelenggarakan Peran dan Fungsi lembaga pemerintah sesuai Akuntabilitas keuangan negara \& membina penyelenggaraan SPIP. berdasarkan Peraturan Presiden No 192 tahun 2014 dan Instruksi Presiden Nomor 9 Tahun 2014,BPKP mempunyai tugas menyelenggarakan urusan pemerintahan di bidang pengawasan keuangan negara/daerah dan pembangunan nasional. Dalam melaksanakan tugas tersebut, BPKP menyelenggarakan 2 fungsi utama, yaitu fungsi pengarahan dan pengoordinasian pengawasan intern, dan fungsi pengawasan intern. Pada akhir tahun 2014, BPKP mendapat penguatan peran melalui Peraturan Presiden No 192 \& Instruksi Presiden No 9 tentang Badan Pengawasan Keuangan dan Pembangunan diantaranya :

a. Berdasarkan mentri keuangan selaku bendahara Umum Negara \& penugasan dari presiden dalam merancang kebijakan nasional pengawasan intern terhadap Akuntabilitas Keuangan Negara/Daerah dan pembangunan Nasional melalui kegiatan Lintas sektoral.

b. Merekonstruksi dan melaksanakan audit, reviu, evaluasi, pemantauan \& kegiatan pengawasan lainnya terhadap pertanggung jawaban Akuntabilitas Penerimaan Negara/daerah dan Pengeluaran keuangan negara/daerah serta pembangunan nasional dan kegiatan lainnya yg seluruh atau sebagian keuangannya dibiayai oleh anggaran negara/daerah, atau subsidi termasuk badan usaha dan badan lainnya yang terdapat perencanaan, pelaksanaan Keuangan atau kepentingan lain dari pemerintah pusat dan pemda serta akuntabilitas pembiayaan keuangan negara/daerah.

c. Badan Pengawasan Keuangan \& Pembangunan (BPKP) bersama aparat pengawasan intern pemerintah lainnya melakukan koordinasi menyelenggarakan pengawasan intern terhadap akuntanbilitas Financial Daerah/Negara dan pembangunan Infrastruktur nasional.

Strategi Dan Kebijakan Pengawasan yang dilakukan oleh BPKP. Strategi yang di lakukan Badan Pengawasan Keuangan dan Pembangunan (BPKP) perwakilan Sulawesi utrara dalam Periode 2015-2019 dalam mengawasi ialah Fokus meningkatkan kwalitas hasil mengawasi Rencana Strategis melalui proses penguatan SPIP,Menguatkan Kemampuan APIP,membangun Kekuatan Tenaga Ahli BPKP perwakilan Sulut. Dalam memujudkan Visi $\&$ Misi dirancang sebagai program-program indikatif. Secara Detail Strategi tertuang dalam 4 point Strategi yaitu :

1. Mendorong menguatkan penyelenggaraan SPIP \& meningkatkan kapasitas pengawasan program pemerintah yang di dukung oleh pengawasan intern.

2. Fokus utama dalaam mengawasi intern pada proyek Strategis nasional yang bersifat Lintas dalam RPJMN Periode 2015-2019, termasuk dalam penguatan Sistem pengendalian Intern program lintas. 
3. Mengawasi Optimalisasi penerimaan negara/Daerah.

4. Usaha mengamankan keuangan Aset Daerah/Negara Termasuk Pencegahan dan membasmi Tindak Pidana Korupsi.

Pelaksanaan Kegiatan Pengawasan. Pelaksanan kegiatan pengawasan dikelompokkan ke dalam 4 fokus, yaitu Pengawalan Pembangunan Nasional, Kontribusi Peningkatan Ruang Fiskal, Pengamanan Aset Negara, dan Peningkatan Governance System.

Peraturan Pemerintah Republik Indonesia Nomor 9 Tahun 2018 Tentang Penerimaan Negara Bukan Pajak (PNBP). Penerimaan negara bukan pajak adalah sumber-sumber penerimaan negara Indonesia yang berasal dari pungutan yang dibayar oleh orang pribadi atau badan, dimana semua hasil penerimaan tersebut dikelola oleh pemerintah yang dimana hasil dari penerimaan tersebut manfaatnya langsung ataupun tidak langsung atas layanan dan pemanfaatan sumber daya dan hak yang diperoleh dari negara, berdasarkan peraturan perundang-undangan penerimaan perpajakan dan hibah yang dikelola dalam mekanisme Anggaran pendapatan dan belanja negara di luar penerimaan pemerintah pusat. Dalam memenuhi kewajiban membayar PNBP sesuai dengan ketentuan peraturan perundangundangan no 9 tahun 2018 wajib bayar adalah wajib pajak atau badan dari dalam maupun luar negeri harus memenuhi kewajiban membayar PNBP sesuai dengan ketentuan yang berlaku. Dalam membiayai belanja negara yaitu PNBP. Potensi PNBP menjadi lumbung penerimaan kas negara dikelompokkan berdasarkan sumber penerimaan yang berbeda yaitu Hasil Perut Bumi,Laba BUMN bagian dari pendapatan,pendapatan Badan Layanan umum. Namun pengelolaan PNBP belum optimal sehingga potensi kontribusinya terhadap penerimaan negara belum dirasakan.

Pengaturan PNBP. Pengaturan PNBP bertujuan untuk :

a. Dalam peningkatan sumber pendapatan negara dari PNBP guna meningkatkan ketahanan fiskal demi kemandirian bangsa yang berkelanjutan dan berkeadilan.

b. Upaya pemerintah memperbaiki kesejahteraan rakyat dan peningkatan pertumbuhan ekonomi yang berkualitas, perbaikan distribusi pendapatan, dan pelestarian lingkungan hidup untuk kesinambungan antar generasi dengan mempertimbangkan aspek keadilan.

c. Pemerintah bertransformasi dalam peningkatan pelayanan kepada masyarakat yang profesional, transparan dan akuntabel dalam mendukung tata kelola pemerintah yang baik.

d. Penetapan tarif atas jenis PNBP berdasarkan peraturan pemerintah Republik Indonesia no 9 pasal tarif spesifik; dan/atau taif ad Valorem.

\section{METODE DAN TEKNIK PENERAPAN IPTEKS}

\subsection{Metode Penerapan Ipteks}

Metode Iptek yang di terapkan menganalisa tugas dan fungsi beserta peran BPKP dalam mengawal dan mengoptimalkan PNBP sesuai aturan yang telah ditetapkan oleh pemerintah.

\subsection{Teknik Penerapan Ipteks}

Menerapkan peraturan yaitu Undang-Undang No. 9 thn 2018 tentang penerimaan negara bukan pajak sesuai dengan Fungsi dan Peran BPKP sesuai Peraturan Presiden no 192 tahun 2014 Tentang BPKP.

\section{PEMBAHASAN}

\subsection{Gambaran Objek Penerapan Ipteks}

Badan Pengawasan Keuangan dan Pembangunan Perwakilan Provinsi Sulut adalah suatu lembaga Pemerintah non kementrian dengan begitu BPKP berada dibawah arahan langsung dan Bertanggung Jawab pada Presiden dengan tugas mengawal Kegiatan pemerintah dalam bidang pengawasan keuangan Daerah/Negara dan pembangunan sektor 
nasional yang merupakan berlokasi di Jalan Diponegoro 1 No 1 Mahakeret Timur, Kecamatan Wenang, kode pos 95112. Badan Pengawasan Keuangan dan Pembangunan yang biasa di singkat BPKP Prov Sulawesi Utara sudah resmi berada di Manado pada tahun 1969 namun masih diarahkan oleh Direktorat Jendral Pengawasan Keuangan Negara Departemen Keuangan dengan nama Kantor Pengawasan Anggaran Negara (KPAN). Resminya berdiri sebagai BPKP pada tahun tahun 1983.Peran BPKP ialah bertanggung jawab langsung kepada Presiden dalam laporannya mengawal akuntabilitas keuangan dan pembangunan dan sudah tersebar melalui kantor perwakilan yang ada Indonesia sebanyak 33 Provinsi dan mempunyai Kantor Pusat di Jalan Pramuka no 33 Jakarta. Kepala Perwakilan BPKP Provinsi Sulawesi Utara saat ini ialah Kwinhatmaka S.E., M.M, dimana beliau Mengarahkan 110 pegawai dalam bagian-bagian seperti Jabatan Fungsional Kepala Bagian Tata Usaha,Kepala Bidang IPP,Kepala Bidang APD, Kepala Bidang (AN), Kepala Bidang Investigasi \& Kepala Bidang program dan pelaporan serta pembinaan APIP (P3APIP).

\subsection{Pembahasan}

Potensi Hambatan dan Pengawasan Pengelolaan Penerimaan Negara Bukan

Pajak. Pada akhir tahun 2014, BPKP mendapat tugas dan tanggung jawab melalui Peraturan Presiden No 192 dan Instruksi Presiden No 9 tentang BPKP dalam menyelenggarakan dan pengoordinasian pegawasan intern BPKP diantaranya ialah melaksanakan evaluasi, reviu,Audit pemantauan dan pengawasan lainnya terhadap perencanaan, pelaksanaan dan pertanggung jawaban akuntabilitas penerimaan negara. Di tahun yang sama, BPK merilis hasil pemeriksaan semester 1 , diantaranya memuat kekurangan penerimaan negara sebanyak 1.120 kasus sebesar Rp. 1.452.944,63 Jt, termasuk didalamnya PNBP. Dalam waktu yang bersamaan tentang pengelolaan PNBP juga dirilis dalam laporan kajian KPK. Dengan adanya Perpres no 192 tahun 2014 mengenai Badan Pengawasan Keuangan dan Pembangunan dan menjadi fokus utama pengawasan BPKP adalah peningkatan ruang fiskal, serta berbagai permasalahan pengelolaan PNBP. Tujuan penelitian melakukan pemetakan proses pengelolaan PNBP dengan menganalisa permasalahan yang mempunyai potensi menghambat pencapaian optimalisasi dan menemukan bentuk pengawasan yang paling cocok untuk mengendalikan permasalahan tersebut. Pengelolaan, hambatan, dan pengawasan dengan unit analisis Kementerian/ Lembaga pengelola PNBP dengan mengambil fokus atau sampel Kementerian Keuangan, Kementerian ESDM, Kementerian Lingkungan Hidup dan Kehutanan, Kementerian Komunikasi dan Informatika, dan Kementerian Kelautan dan Perikanan merupakan variabel yang di teliti. Usaha agar mencapai tujuan penelitian tersebut, penelitian ini mengumpulkan data dari unit analisis dengan membatasi pada jenis PNBP yang bersumber dari sumber daya alam yaitu iuran tetap mineral dan batubara, royalti mineral dan batu batubara, dana reboisasi, provisi sumber daya alam, pengganti nilai tegakan, pungutan pengusahaan perikanan, dan pungutan hasil perikanan. Data dikumpulkan melalui wawancara atau focus group discussion dan dokumentasi. Selanjutnya data tersebut dikelompokkan, ditelaah, dianalisis, Puslitbangwas BPKP dan dibandingkan dengan teori atau peraturan untuk melihat adanya kesenjangan atau perbedaan. Perbedaan atau permasalahan tersebut diidentifikasi untuk melihat hubungannya dengan optimalisasi PNBP dan bentuk pengawasan yang dibutuhkan. Dalam kategori dan menganalisis, peneliti menggunakan unsur pengelolaan yaitu merencanaan, pengorganisasian, pelaksanaan, pengendalian, pemeriksaan dan pengawasan. Dapat disimpulkan bahwa perencanaan PNBP belum mencapai tujuan dengan baik. Penetapan potensi PNBP tidak ada, sehingga di tahun terakhir ditambah perkiraan lebih kurang $10 \%$ dari penyusunan target tidak berdasarkan potensi tetapi didasarkan realisasi.dalam menghitung target maupun menghitung realisasi, pihak pengelola menggunakan tarif yg ditetapkan dalam peraturan pemerintah pada tahun 2012 untuk minerba, tahun 2014 untuk kehutanan, tahun 2010 untuk telekomunikasi, dan tahun 2012 untuk minerba, tahun 2014 untuk kehutanan, tahun 2010 untuk telekomunikasi, dan tahun 
2006 untuk perikanan.Tarif PNBP untuk perikanan tidak sesuai karena harga ikan dengan harga satuan ikan yang ditetapkan jauh berbeda, sehingga berdampak adanya ineffciency. Kementerian Keuangan dan Direktorat Jenderal Pajak mempunyai peran dalam pengelola PNBP memungut \& menyetorkan, dan BPKP sebagai instansi pemeriksa yang berfungsi memeriksa sesuai periode yang telah ditetapkan. Struktur pengelolaan PNBP menuju tiga pihak yang memisahkan fungsi dan tanggung jawab (good separation duties). Kementerian Keuangan sebagai penanggung jawab atau yang di beri kuasa menyimpan PNBP dalam kas negara. Struktur di kementrian keuangan sebagai pengelola PNBP secara nasional, berada di Direktorat PNBP di bawah Dirjen Anggaran tetapi kewenangan pelaksanaan dan SDM-nya terbatas. Pada tahun 2015 penyetoran mulai menggunakan aplikasi simponi agar mempermudah menyetorkan PNBP langsung ke kas negara. Dengan menyerahkan langsung ke kas negara sesuai dengan UU no 20 Tahun 1997 pasal 4, peraturan pemerintah nomor 29 tahun 2009, peraturan mentri keuangan no 3/PMK.02/2013. Prosedur pengoordinasikan sesuai PP no 22/2015 pasal 3 menyebutkan bahwa Menkeu berkoordinasi dengan instansi pemerintah dalam rangka pemeriksaan PNBP. Tetapi terjadi kendala dalam proses koordinasi instansi pengelola dengan kementrian keuangan belum jalan sejajar dengan baik dalam perhitungan potensi. Demikian koordinasi antara instansi pemerintah mengelola PNBP. Kementrian Keuangan bersama BPKP,dalam usaha mengendalikan dan mengelola PNBP yang dilakukan Kementerian Keuangan terhadap Direktorat Jendral Pajak dalam pengelolaan PNBP, tetapi yang dilakukan oleh Direktorat Jenderal Anggaran ini yang belum mencapai target karena kurangnya sumber daya manusia dan dana. Kewenangan tidak di landasi dengan sanksi yang dikenakan jika instansi pemerintah tidak melaporkan kewajibannya, pengendalian di setiap kementrian seharusnya mampu memitigasi risiko yang menyebabkan tidak optimalnya PNBP. Instansi pengawasan intern pemerintah yaitu BPKP dan Inspektorat Jendral melakukan review dalam pengelolaan PNBP yang sudah di lakukan oleh instansi yang terkait tetapi kegiatan tersebut masih terbatas pemeriksaaan terhadap kepatuhan wajib bayar. Kegiatan mengawasi intern mengelola PNBP ada kaitannya dengan kegiatan pengawasan pengelolaan sumber PNBP itu sendiri, seperti pengelolaan pertambangan mineral dan batubara, pengelolaan kehutanan, pengelolaan perikanan. Dari sumber pendapatan tersebut menjadi tolak ukur keberhasilan mengawasi kegiatan pengawasan intern. Berdasarkan undang-undang no 20 tahun 1997 BPKP memiliki wewenang untuk melaksanakan pemeriksaan dalam mengelola Penerimaan Negara Bukan Pajak, tetapi kewenangan tersebut dapat dilaksanakan hanya hanya ketika ada permintaan dari Kementerian Keuangan dan Direktorat Jendral Pajak. Sehingga BPKP kurang mengoptimalkan dalam melaksanakan fungsinya sebagai instansi pemeriksa dalam struktur mengelola PNBP, maka dari itu BPKP mendorong adanya Amandemen Undang-undang no 20 tahun 1997 terkait pemeriksaan PNBP. Dalam pp no 60 tahun 2008 menjelaskan fungsi BPKP sebagai Pembina Aparat Pengawasan Intern Pemerintah (APIP) dan sebagai Pembina Sistem Pengendalian Intern Pemerintah (SPIP).Tujuan SPIP ialah mempermudah tugas pemerintah dalam penyelengara berjalan efektif, efisien, akuntabel dan independen karena BPKP tidak hanya mengawasi namun juga pengarahan dalam membina pengelolaan penerimaan negara. Sejak Peraturan Presiden no 192 tahun 2014 baru di terbitkan BPKP mendapatkan penguatan peran dimaksudkan untuk pengawasan intern yang akuntabel dan independen. BPKP sebagai auditor internal pemeritah atau membantu Presiden berkewajiban untuk memastikan bahwa birokrasi (governance) intansi pemerintah mendukung mencapai tujuan dengan menerapkan manajemen risiko (risk) serta pengendalian (control). BPKP sebagai APIP yang memiliki kewenangan berdasarkan undang undang dan perpres dalam pengelolaan PNBP, harus proaktif, inisiatif, antipatif membantu merumuskan, merencanakan, melaksanakan kebijakan pengawasan pengelolaan PNBP. 


\section{KESIMPULAN DAN SARAN}

\subsection{Kesimpulan}

Dalam pengawal dan mengawasi penerimaan negara dan penerimaan negara bukan pajak bersama Kementrian Keuangan dan Direktorat Jendral Pajak mempunyai peran dalam pengelola PNBP memungut \&menyetorkan, dan BPKP sebagai instansi pemeriksa yang berfungsi memeriksa sesuai periode yang telah ditetapkan. Struktur pengelolaan PNBP menuju tiga pihak yang memisahkan fungsi dan tanggung jawab (good separation duties). Kementrian Keuangan sebagai penanggung jawab atau yang di beri kuasa menyimpan PNBP dalam kas negara. Struktur di Kementrian Keuangan sebagai pengelola PNBP secara nasional, berada di direktorat PNBP di bawah Dirjen Anggaran tetapi kewenangan pelaksanaan dan SDM-nya terbatas. Diantara peran BPKP adalah melaksanakan Audit, Reviu, Evaluasi, mengawasi \& kegiatan pengawasan lainnya melalui merencanakan, melaksanakan serta Bertanggung jawaban Akuntabilitas penerimaan negara dan sinergi serta pengoordinasian penyelenggaraan pengawasan intern atas akuntabilitas keuangan negara.

\subsection{Saran}

Dari pembahasan dan kesimpulan yang telah dibuat, dalam mengoptimalisasi penerimaan pajak dan penerimaan negara bukan pajak yang di kawal oleh BPKP Provinsi Sulawesi Utara dalam upaya meningkatkan penerimaan negara berasal dari pajak sesuai dengan aturan yang berlaku.

\section{DAFTAR PUSTAKA}

Dinarjito, A . 2017. Pengelolaan penerimaan Negara Bukan pajak : Study kasus pada kantor pertahanan wilayah provinsi daerah istimewa Yogyakarta . Jurnal Manajemen Keuangan Publik, volume 1 no 1, 57-69

Instruksi Presiden No 9 Tahun 2014, BPKP mempunyai tugas mengawal Kegiatan pemerintahan di bidang pengawasan keuangan negara/daerah dan pembangunan nasional

Kurniasih, D. 2016. Pembahuruan Pengelolaan Penerimaan Negara . Jakarta. Jurnal Rechts Vinding Media Pembinaan Hukum NasionalBuletin Teknis Standar Akuntansi Pemerintahan. Akuntansi Aset Tetap berbasis Akrual Volume 5 no 2, 213-228

Keputusan Presiden Republik Indonesia Nomor 31 Tahun 1983 Tentang Badan Pengawasan Keuangan Dan Pembangunan

Laporan Potensi Hambatan dalam Mengawasi Pengelolaaan Penerimaan Negara bukan Pajak 30 Juli 2017

Peraturan Presiden Republik Indonesia Nomor 192 Tahun 2014 tentang Badan Pengawasan Keuangan dan Pembangunan

Peraturan Pemerintah (PP) Nomor 01 Tahun 2004 Tentang Sistem Pengendalian Intern Pemerintah (SPIP)

Peraturan Pemerintah Nomor 73 tahun 1999 Tentang Tata Cara Penggunaan PNBP yang bersumber dari kegiatan tertentu

Peraturan Pemerintah Republik Indonesia Nomor 47 tahun 2010 Tentang Jenis dan Tarif atas jenis penerimaan negara bukan pajak yang berlaku pada Badan Pengawasan Keuangan dan Pembangunan

Peraturan Presiden Republik Indonesia Nomor 75 Tahun 2017 tentang penilaian kembali barang milik daerah

Peraturan Menteri Keuangan Republik Indonesia Nomor 3/pmk.02/2013 tentang cara penyetoran penerimaan negara Bukan Pajak oleh Bendahara Penerimaan

Peraturan Pemerintah Republik Indonesia Nomor 3 Tahun 2018 tentang Jenis dan Tarif atas Jenis Penerimaan Negara Bukan Pajak Yang berlaku pada Kementerian Keuangan 